\title{
Epidemiology and reporting of osteoporotic vertebral fractures in patients with long-term hospital records based on routine clinical CT imaging
}

\author{
M. T. Löffler ${ }^{1,2}$ D $\cdot$ M. Kallweit ${ }^{1} \cdot$ E. Niederreiter ${ }^{1} \cdot$ T. Baum $^{1} \cdot$ M. R. Makowski ${ }^{3} \cdot$ C. Zimmer $^{1} \cdot$ J. S. Kirschke $^{1}$
}

Received: 17 May 2021 / Accepted: 21 September 2021 / Published online: 14 October 2021

(c) The Author(s) 2021, corrected publication 2022

\begin{abstract}
Summary Osteoporotic vertebral fractures signify an increased risk of future fractures and mortality and can manifest the diagnosis of osteoporosis. We investigated the prevalence of vertebral fractures in routine CT of patients with long-term hospital records. Three out of ten patients showed osteoporotic vertebral fractures (VFs) corresponding to the highest rates reported in European population-based studies.

Introduction VFs are a common manifestation of osteoporosis, which influences future fracture risk. Their epidemiology has been investigated in population-based studies. However, few studies report the prevalence of osteoporotic VF in patients seen in clinical routine and include all common fracture levels of the thoracolumbar spine. The purpose of this study was to investigate the prevalence of osteoporotic VF in patients with CT scans and long-term hospital records and identify clinical factors associated with prevalent VFs.

Methods All patients aged 45 years and older with a CT scan and prior hospital record of at least 5 years that were seen in the study period between September 2008 and May 2017 were reviewed. Imaging requirements were a CT scan with sagittal reformations including at least T6-L4. Patients with multiple myeloma were excluded. Fracture reading was performed using the Genant semi-quantitative method. Medical notes were reviewed for established diagnoses of osteoporosis and clinical information. Clinical factors (e.g. drug intake, chemotherapy, and mobility level) associated with prevalent VF were identified in logistic regression.

Results The study population consisted of 718 patients (228 women and 490 men; mean age $69.3 \pm 10.1$ years) with mainly cancer staging and angiography CT imaging. The overall prevalence of VFs was $30.5 \%$, with non-significantly more men showing a fracture (32.5\%) compared to women $(26.3 \% ; p>0.05)$. Intake of metamizole for $\geq 3$ months was significantly associated with a prevalent VF. Medical records did not include information about bone health in $90 \%$ of all patients. CT reports did mention a VF in only $24.7 \%$ of patients with a prevalent VF on CT review.

Conclusion Approximately $30 \%$ of elderly patients with CT imaging and long-term hospital records showed VFs. Only onequarter of these patients had VFs mentioned in CT reports. Osteoporosis management could be improved by consequent reporting of VFs in CT, opportunistic bone density measurements, and early involvement of fracture liaison services.
\end{abstract}

Keywords Fragility fracture $\cdot$ Oncologic patients $\cdot$ Opportunistic screening · Osteoporosis · Vertebral fractures

M. T. Löffler

m_loeffler@web.de

1 Department of Diagnostic and Interventional Neuroradiology, School of Medicine, Klinikum Rechts Der Isar, Technical University of Munich, Munich, Germany

2 Department of Diagnostic and Interventional Radiology, University Medical Center Freiburg, Freiburg im Breisgau, Germany

3 Department of Diagnostic and Interventional Radiology, School of Medicine, Klinikum Rechts Der Isar, Technical University of Munich, Munich, Germany

\section{Introduction}

Osteoporosis is a metabolic bone disease characterized by impaired bone strength, increasing the individual risk of fracture [1]. Osteoporosis affects the population worldwide, particularly the elderly in developed countries [2]. The main problem of osteoporosis is the lack of early symptoms: Osteoporotic patients remain asymptomatic until a fracture occurs. Moreover, up to three-quarters of osteoporotic vertebral fractures (VFs) do not receive clinical attention [3, 
4], because they remain asymptomatic or no conclusion is drawn from unspecific back pain to a potential fragility fracture.

VFs are among the most common and most consequential osteoporotic fractures [5]. Prior VFs pose the highest relative risk for subsequent VFs compared to the risk for subsequent fractures at other sites [6]. VFs are associated with an approximately twofold increased mortality risk for 5 to 10 years, only surpassed by hip fractures [7]. Interestingly, VFs pose a higher mortality risk to men than women $[7,8]$. However, all types of osteoporotic fractures in the elderly foreshadow a high risk of poor outcomes, so that early intervention is strongly advised [9]. Anti-osteoporotic treatment mainly targets fracture risk, but has shown to also influence mortality and health-related quality of life as in the case of zoledronic acid [10,11]. Medical treatment can specifically target patients with a very high-risk profile, but generally long-term management is required [12].

The first step in prevention is to identify individuals at high risk of fracture. Screening approaches target elderly people at age 65 or 70 years and assess fracture risk by known risk factors and optional bone densitometry [12]. Population-based studies documented that among potential risk factors, previous VFs were the most important risk factor for future VFs [13] and that VFs represent an important risk factor for future fractures in general [14]. The prevalence of osteoporotic VFs among Europeans older than 50 years ranges between 18 and 26\% [15]. New approaches to improve fracture risk assessment include the use of clinical CT scans acquired for other purposes to screen for previously undetected VFs or to opportunistically evaluate bone mineral density (BMD) $[12,16]$. Recently, a UK national audit including over 6000 patients aged 70 years and older as seen in 127 radiology departments reported a prevalent VF in CT imaging in $21 \%$ of patients [17].

We hypothesize that the prevalence of osteoporotic VFs exceeds $25 \%$ in a typical population of patients seen in hospital routine for long term follow-up. Therefore, we performed a monocenter retrospective study of patients with CT imaging and at least a 5-year hospital record to evaluate the prevalence of VFs. Moreover, we investigate the association of prevalent VFs with clinical factors.

\section{Methods}

\section{Ethics approval}

The present study was approved by the local institutional review board (ethics committee's reference number 5022/11A2) and was conducted in accordance with the Declaration of Helsinki. The requirement for informed consent was waived by the institutional review board due to the retrospective character of imaging data collection and post hoc analysis.

\section{Study population}

Study patients were identified from the local database of the Klinikum rechts der Isar of the Technical University Munich, a 1.161 bed university hospital located in southern Germany. The hospital is annually treating more than 60,000 hospitalized patients and additionally around 250,000 outpatients. All patients aged 45 years and older were eligible that had an index CT scan of the chest, abdomen, or pelvis performed in the outpatient clinic or during admission between September 1, 2008, and May 31, 2017, and that had a prior medical record of at least 5 years in the hospital database. In case of recurrent patients or patients with multiple CT scans in the study period, the first CT scan satisfying the inclusion criteria (see below) was assessed. In very few exceptions ( $n=4$ of final study population), patients had CT scans performed in external institutions prior to clinic visit or hospital admission, and imaging data was imported from CDROM into the institutional database. The study population was then selected based on imaging criteria and exclusion criteria. Imaging criteria for inclusion were a CT scan with sagittal reformations showing at least vertebrae T6 to L4, because sagittal reformations are required for reliable detection of VFs [18] and fractures commonly affect these levels [19]. Patients with high-energy fractures due to trauma were excluded. Moreover, patients with multiple myeloma were excluded, because this disease shares a defining characteristic with osteoporosis and fractures due to deteriorated bone strength cannot be clearly attributed to either one of these diseases [20].

\section{CT image acquisition}

All CT scans of included patients were acquired on multidetector CT scanners, partly after administration of either both oral (Barilux Scan; Sanochemia Diagnostics, Neuss, Germany) and intravenous (Iomeron 400; Bracco, Konstanz, Germany) contrast medium or only intravenous contrast material. Scans were performed in the hospital on a Philips Brilliance 64, Philips iCT 256, Philips Ingenuity Core 128, Philips IQON (Philips, Best, The Netherlands), Siemens Biograph 64, Siemens Biograph 128, Siemens Definition AS, Siemens Definition AS +, or Siemens Sensation Cardiac 64 scanner (Siemens Healthineers, Erlangen, Germany)_with the exception of four scans that were performed on a Siemens Emotion 16 scanner in another institution. Scans were acquired in helical mode with a slice thickness of $0.9-1 \mathrm{~mm}$ using adaptive tube load at a peak tube voltage of $120 \mathrm{kVp}$ - with few exceptions using $100 \mathrm{kVp}, 130 \mathrm{kVp}$, or $140 \mathrm{kVp}$. 


\section{Fracture reading}

CT scans were evaluated for prevalent fractures at each vertebral level. Only thoracolumbar vertebrae were evaluated, as fractures are rare and usually of non-osteoporotic origin at the cervical spine [19]. Fracture reading was performed in consensus by one trained medical student $(\mathrm{MH})$ and one radiologist (MTL) with 5 years of experience. Prevalent VFs were classified using the semi-quantitative method by Genant [21]. VFs were graded as mild for a height loss $\geq 20 \%$ and $<25 \%$ (grade 1), as moderate for a height loss of $\geq 25 \%$ and $<40 \%$ (grade 2), and as severe for a height loss $\geq 40 \%$ (grade 3 ). With reference to the recent discussion on grading osteoporotic fractures [22], it shall explicitly be mentioned that non-osteoporotic deformities were not graded as osteoporotic fractures, in line with the original description by Genant [21]. Moreover, in patients with neoplastic disease and suspicion of spinal lesions, all available imaging (CT and MRI) was additionally reviewed by an attending radiologist (JSK) in order to distinguish between osteoporotic or pathologic fractures [23]. Any patient with at least one VF that could be attributed to osteoporosis was counted as a patient with $\geq 1$ osteoporotic VF irrespective of the presence of additional pathologic VFs.

\section{Clinical information and $\mathrm{CT}$ imaging reports}

For all included patients, any discharge or consultation notes in the hospital database closest to the time of the CT scan were reviewed for primary diagnosis (free text and ICD10 codes), current medications, chemotherapy, and level of immobility. In knowledge of primary diagnoses, we summarized indications for $\mathrm{CT}$ imaging into 5 categories: staging of solid cancer, non-solid cancer, CT angiography, assessment of spinal stenosis, and other indications. Based on prescriptions noted in medical records, we assessed intake of medications for at least 3 months during a period of 5 years prior to the index CT scan. Assessed medications included nonsteroidal anti-inflammatory drugs, metamizole, opioids, immunosuppressive drugs, glucocorticoids, vitamin $\mathrm{D}$, and bisphosphonates. Due to the retrospective study and sparse data, we summarized chemotherapeutic medications with adverse effects on bone metabolism in order to get sufficient statistical power. This mainly included chemotherapeutics and other medications for breast cancer treatment (e.g. tamoxifen, aromatase inhibitors, and GnRH antagonist drugs). Moreover, bisphosphonates were the most consistently prescribed anti-osteoporotic drugs we could find in medical notes and, for instance, Denosumab was only prescribed in 3 patients. Therefore, we only calculated statistics for bisphosphonates. The level of immobility was stratified into an ordinal scale of short (postoperative immobility, fatigue), medium (recurrent postoperative immobility, intensive care stay for longer periods of time, dementia, reduced general condition, help needed with walking [Barthel-Index], Karnovsky-Index $<70 \%$, ECOG-Index 2, NYHA III), and prolonged immobility (cachexia, paraplegia, decubitus, Parkinson's disease, muscular dystrophy, ankylosing spondylitis, help needed with walking, grooming, and toilet use [Barthel-Index], Karnovsky-Index $<50 \%$, COPD GOLD IV, peripheral artery disease stadium III/ IV, NYHA IV, ECOG-Index 3-4). We also reviewed the available records of all patients for established diagnoses of osteoporosis or low bone mass. Furthermore, imaging reports of CT scans of fractured patients were reviewed for any mention of deteriorated bone quality or non-traumatic spinal fractures. Valid terminology for deteriorated bone quality was "osteopenia", "osteopenic bone structure", or "decrease bone mineral content" (German: "Osteopenie", "osteopene Knochenstruktur", or "Knochen(mineral)salzminderung"). The terminology used to describe the fracture related abnormalities was analyzed in more detail. We distinguished between the primary term "fracture" (German: "Fraktur", "Deckplatteneinbruch", or "Grundplatteneinbruch") and secondary terms such as "deformity", "sintering", "impression", "height loss", "height reduction", or "Schmorl's node" (German: "Deformität", "Sinterung", "Impression", "Höhenminderung", "Keilwirbelbildung", or "Schmorlscher Knoten").

\section{Statistical analysis}

Patients were stratified into age groups with $<50,50-59$, $60-69,70-79$, and $\geq 80$ years of age, respectively. Association of selection status (included or excluded from all eligible patients) and age groups was tested using chi-squared statistics. Descriptive statistics such as mean, standard deviation, and frequency were used to summarize prevalence of VFs, clinical characteristics, and information from CT reports. The proportions of CT indications were compared between men and women using chi-squared test. Any osteoporotic fracture of grade 1 or higher was counted as an osteoporotic VF. Absolute numbers, frequencies, and $95 \%$ confidence intervals (CI) of prevalent VFs were given. The frequency of VFs was compared between men and women using independent samples $t$-test. Clinical characteristics associated with prevalent VFs were identified in univariate logistic regression models. Multivariate logistic regression models were then used to identify predictors of prevalent VF, adjusting for clinical variables that were significant in univariate analysis with a two-sided $p$-value $<0.05$. Statistical analyses were performed using SPSS (version 26; IBM) and RStudio (version 1.4.1106; RStudio). Level of statistical significance was set at $p<0.05$. 


\section{Results}

There were 2057 patients aged 45 years or older seen in the outpatient clinic or admitted to the hospital during the study period, which had a CT scan of the chest, abdomen, or pelvis and a well-documented medical record in the hospital over the last 5 years. Of these, 718 patients were included that met the imaging criteria and had no diagnosis of multiple myeloma (Fig. 1). The study population had a mean age of $69.3 \pm 10.1$ years ranging from 45.8 to 93.4 years. The mean age did not significantly differ between 228 women $(69 \pm 9.4$ years) and 490 men $(69.4 \pm 10.5$ years; $p=0.58)$. The age distribution of 718 included patients did not significantly differ from 1339 patients that were excluded due to imaging criteria and multiple myeloma $(p=0.168$; Table S1). Indications for CT were staging of solid cancer $(n=502)$, CT angiography $(n=147)$, staging of non-solid cancer $(n=53)$, spinal stenosis $(n=11)$, or other reasons $(n=5$; Table 1$)$. The proportion of women who had CT for staging of solid cancer was significantly higher and for CT angiography was significantly lower compared to men, respectively (both $p<0.001$; Table S2).

A total of 12.167 thoracolumbar vertebrae were assessed for fractures with most scans covering the entire thoracolumbar spine (Fig. 2). Of the 718 patients, 219 patients showed $\geq 1$ osteoporotic VFs $(30.5 \%)$ and 25 patients showed only pathologic VFs (3.5\%). The overall prevalence of osteoporotic VFs was $26.3 \%$ in women and $32.5 \%$ in men, without significant difference between sexes $(p=0.097)$. Most fractures occurred at the thoracolumbar junction with the peak at level L1 and at the mid-thoracic spine with a local maximum at level T8 (Fig. 2). An example case of a patient with osteoporotic VFs is shown in Fig. 3.

Stratified into age groups, fracture prevalence steadily increased from 19.8\% (CI 13.2-28.0\%) at age 50-59 years up to $38.9 \%$ (CI $29.3-49.2 \%$ ) at age 80 years and older
(Table 2, Fig. 4). In women, fracture prevalence was $15.6 \%$ (CI $6.2-30.9 \%$ ) at age $50-59$ years, increased to $28.2 \%$ (CI $20.2-37.4 \%$ ) at age $70-79$ years, and continued to rise to $50 \%$ (CI 28.4-71.6\%) at age 80 years and older. In men, fracture prevalence was $21.5 \%$ (CI 13.6-31.5\%) at aged $50-59$ years and seemingly levelled at age $60-69$ years with $35.8 \%$ (CI 28.1-44.2\%) with minimal increase until age 80 years and older with $36.1 \%$ (CI 25.7-47.6\%).

Age was significantly associated with the prevalence of osteoporotic VFs $(p=0.001)$ and remained to be in multivariate analysis $(p=0.002$; Table 1$)$. There was no significant association between a certain $\mathrm{CT}$ indication and the prevalence of an osteoporotic VF (all $p>0.05$; Table 1 ). However, patients with CT angiography showed a tendency for a higher prevalence rate of VFs (36.7\%) compared to other CT imaging indications $(p=0.066)$. Moreover, the prevalence of osteoporotic VFs was significantly associated with intake of metamizole and Vitamin D for at least 3 months ( $p=0.013$ and $p=0.045$, respectively; Table 1 ). Of those factors, prolonged metamizole intake remained a significant predictor for a prevalent VF in multivariate analysis $(p=0.011)$. There was a tendency of more patients with VFs experiencing longer periods of immobility that did not reach statistical significance $(p=0.067)$. The association of patients without prevalent VFs taking bisphosphonates for at least 3 months did not reach statistical significance due to sparse data $(p=0.057)$. Clinical information was not available concerning immobility for $n=61$, chemotherapy for $n=52$, and drug intake for $n=75$ patients.

Medical notes in the hospital database listed an established diagnosis of osteoporosis or low bone mass in 38 patients $(5.3 \%)$ and ruled out such a diagnosis in 4 patients $(0.6 \%)$, while in the majority of 676 patients, no information related to bone health could be found (94.1\%; Table 3). Of all 219 fractured patients, CT reports mentioned an osteoporotic VF in only 54 patients (24.7\%),
Fig. 1 Flow diagram of study cohort with osteoporotic vertebral fractures (VFs)

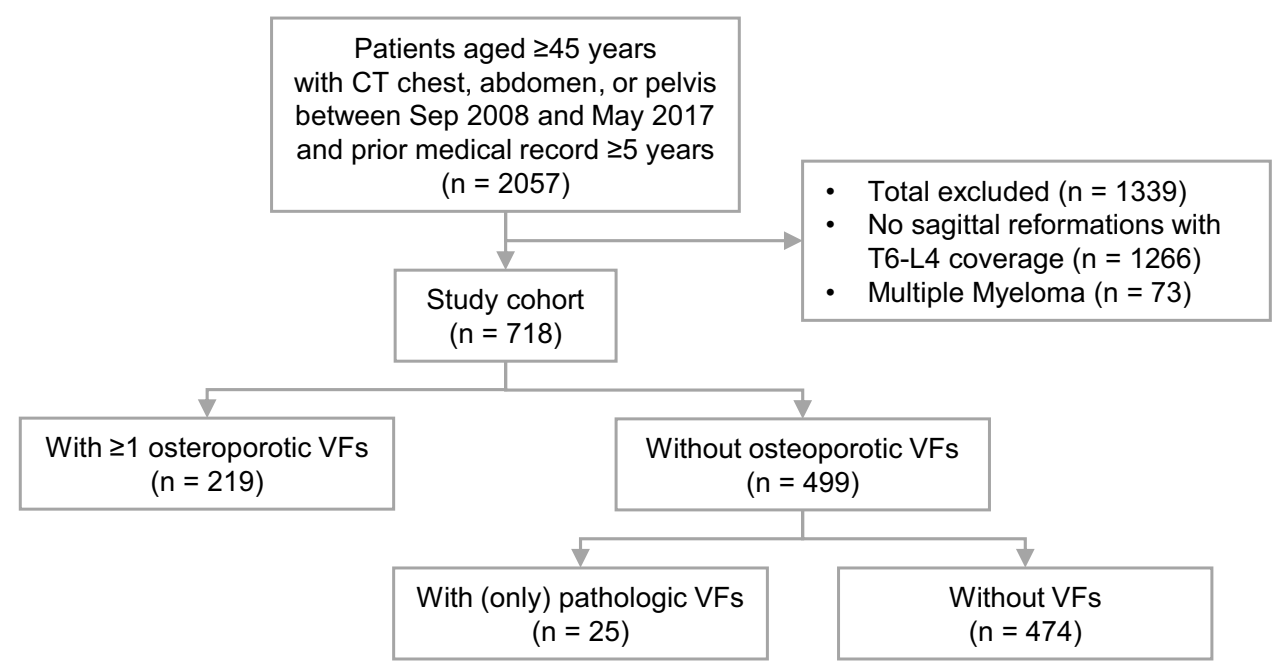


Table 1 Characteristics of study population and its association with the prevalence of osteoporotic vertebral fractures (VFs)

\begin{tabular}{|c|c|c|c|c|c|c|c|}
\hline & \multirow[t]{2}{*}{$\geq 1$ osteoporotic VF } & \multirow[t]{2}{*}{ No osteoporotic VF } & \multirow[t]{2}{*}{ Total } & \multicolumn{2}{|l|}{ Univariate analysis } & \multicolumn{2}{|l|}{ Multivariate analysis } \\
\hline & & & & OR $(95 \% \mathrm{CI})$ & $p$-value & OR $(95 \%$ CI $)$ & $p$-value \\
\hline All, $n(\%)$ & $219(30.5 \%)$ & $499(69.5 \%)$ & 718 & & & & \\
\hline Female, $n(\%)$ & $60(26.3 \%)$ & $168(73.7 \%)$ & 228 & $0.74(0.52-1.06)$ & 0.097 & & \\
\hline Age at CT, years, mean $\pm \mathrm{SD}$ & $71.1 \pm 9.8$ & $68.5 \pm 10.2$ & $69.3 \pm 10.1$ & $1.03(1.01-1.04)$ & 0.001 & $1.03(1.01-1.05)$ & 0.002 \\
\hline \multicolumn{8}{|l|}{ CT indication, $n(\%)$} \\
\hline Solid cancer & $147(29.3 \%)$ & $355(70.7 \%)$ & 502 & $0.83(0.59-1.17)$ & 0.28 & & \\
\hline CT angiography & $54(36.7 \%)$ & $93(63.3 \%)$ & 147 & $1.43(0.98-2.09)$ & 0.066 & & \\
\hline Non-solid cancer & $14(26.4 \%)$ & $39(73.6 \%)$ & 53 & $0.81(0.43-1.52)$ & 0.503 & & \\
\hline Spinal stenosis & $3(27.3 \%)$ & $8(72.7 \%)$ & 11 & $0.85(0.22-3.24)$ & 0.815 & & \\
\hline Other & $1(20 \%)$ & $4(80 \%)$ & 5 & $0.57(0.06-5.11)$ & 0.613 & & \\
\hline Immobility level, $n(\%)$ & & & & $1.20(0.99-1.46)$ & 0.067 & & \\
\hline $0=$ no & $143(28.6 \%)$ & $357(71.4 \%)$ & 500 & & & & \\
\hline $1=$ short & $25(34.7 \%)$ & $47(65.3 \%)$ & 72 & & & & \\
\hline $2=$ medium & $21(36.8 \%)$ & $36(63.2 \%)$ & 57 & & & & \\
\hline $3=$ prolonged & $11(39.3 \%)$ & $17(60.7 \%)$ & 28 & & & & \\
\hline Chemotherapy, $n(\%)$ & $59(28.9 \%)$ & $145(71.1 \%)$ & 204 & $0.85(0.59-1.21)$ & 0.364 & & \\
\hline \multicolumn{8}{|c|}{ Drug intake for at least 3 months, $n(\%)$} \\
\hline Glucocorticoids & $4(16 \%)$ & $21(84 \%)$ & 25 & $0.41(0.14-1.21)$ & 0.105 & & \\
\hline $\begin{array}{l}\text { Immunosuppressive } \\
\text { drugs }\end{array}$ & $3(16.7 \%)$ & $15(83.3 \%)$ & 18 & $0.43(0.12-1.51)$ & 0.188 & & \\
\hline $\begin{array}{l}\text { Nonsteroidal anti-inflam- } \\
\text { matory drugs }\end{array}$ & $1(12.5 \%)$ & $7(87.5 \%)$ & 8 & $0.31(0.04-2.53)$ & 0.273 & & \\
\hline Metamizole & $9(64.3 \%)$ & $5(35.7 \%)$ & 14 & $4.06(1.34-12.28)$ & 0.013 & $4.94(1.45-16.80)$ & 0.011 \\
\hline Opioids & $15(42.9 \%)$ & $20(57.1 \%)$ & 35 & $1.69(0.85-3.37)$ & 0.136 & & \\
\hline Vitamin D & $26(41.3 \%)$ & $37(58.7 \%)$ & 63 & $1.72(1.01-2.94)$ & 0.045 & $1.58(0.92-2.73)$ & 0.099 \\
\hline Bisphosphonates & $4(14.3 \%)$ & $24(85.7 \%)$ & 28 & $0.35(0.12-1.03)$ & 0.057 & & \\
\hline
\end{tabular}

$\mathrm{CI}=95 \%$ confidence interval, $\mathrm{OR}=$ odds ratio, $\mathrm{SD}=$ standard deviation. There was no data available on immobility for $n=61$, on chemotherapy for $n=52$, and on drug intake for $n=75$ patients

Fig. 2 Number of visualized vertebrae and proportion of vertebrae with osteoporotic vertebral fractures (VFs) stratified by level

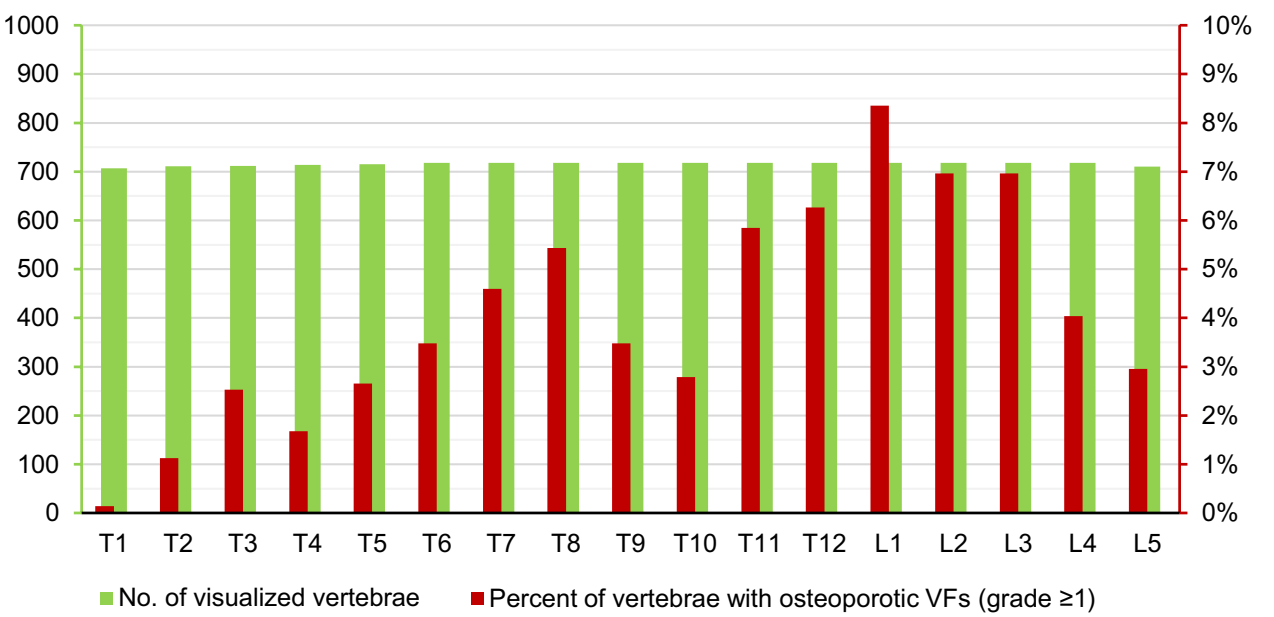




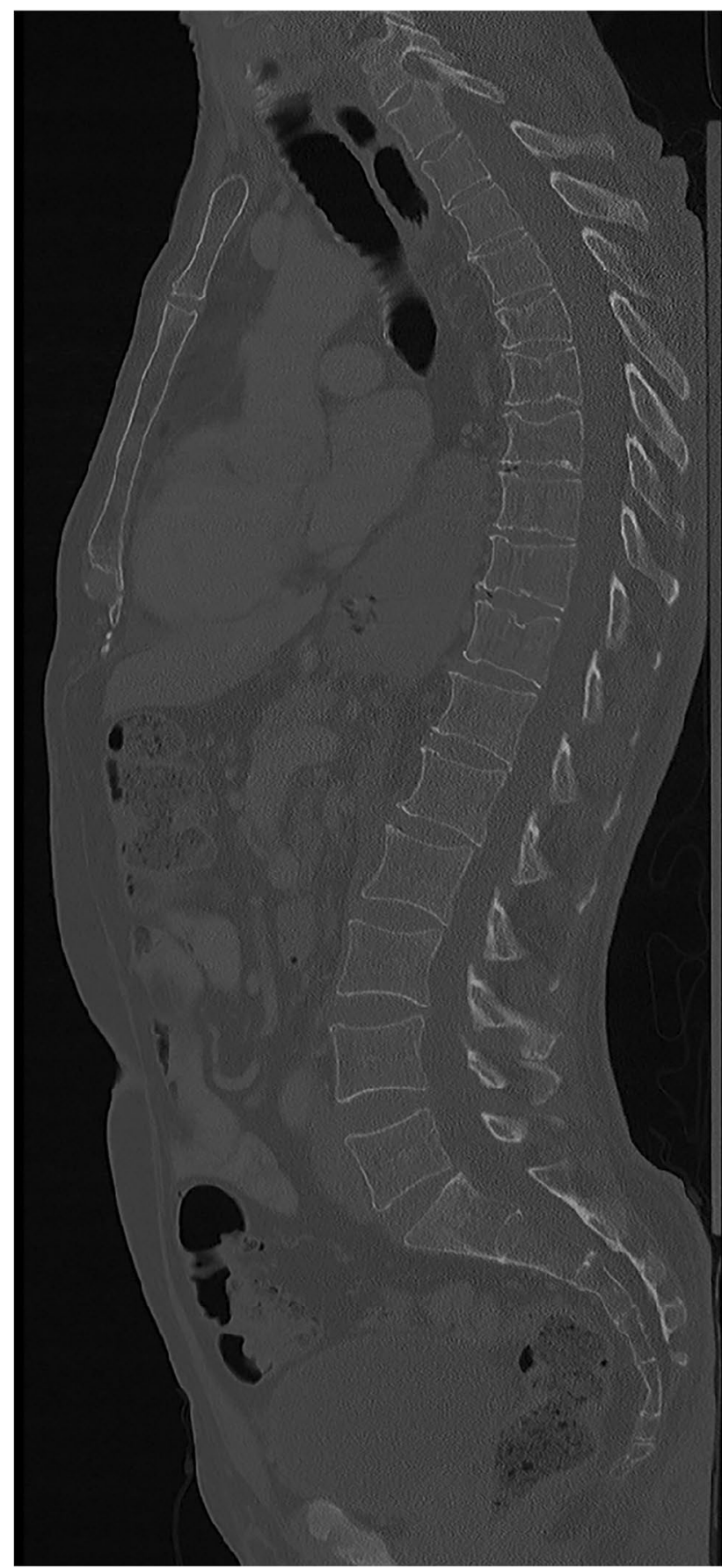

Fig. 3 Contrast enhanced CT scan of a 61-year-old male patient performed for follow-up of esophageal cancer after esophagectomy showing osteoporotic vertebral fractures at T6-8, T10, and T11. The patient's medical records and CT imaging report did not include any information related to suspected low bone mass or osteoporosis

used secondary terminology referring to a vertebral abnormality with or w/o mentioning deteriorated bone quality in 26 patients $(11.9 \%)$, and only mentioned deteriorated bone quality in 11 patients ( $5 \%$; Table 4 ).

\section{Discussion}

This study investigated the prevalence of VFs in CT scans of a population of mainly oncologic and vascular patients with long-term hospital records and aged 45 years and older. Furthermore, clinical factors associated with prevalent VFs were identified. The fracture prevalence was $26 \%$ for women and $32 \%$ for men. We observed a marked increase in fracture prevalence with age reaching $28 \%$ for women in their 70 s and $36 \%$ for men in their $60 \mathrm{~s}$. Fracture prevalence continued to increase with age, particularly for women. The clinical awareness of low bone mass or osteoporosis was very low, as medical notes in only $6 \%$ of all patients referred to bone health. More than half of $\mathrm{CT}$ reports of patients with prevalent VFs (58\%) did not mention these fractures or any suspicion of decreased bone quality.

Not surprisingly, increasing age was the most significant predictor of prevalent VFs (multivariate $p=0.002$ ). Furthermore, we found that metamizole intake for at least 3 months was significantly associated with having a VF in CT review (multivariate $p=0.022$ ). This seems comprehensible as the already low clinical awareness of VFs becomes even more diminished once symptoms are blocked by pain relievers [4]. Patients receiving antiresorptive treatment with bisphosphonates showed a clear trend towards lower rates of prevalent VFs (14\%), but this association did not reach statistical significance due to limited data $(p=0.057)$.

Prevalence rates of osteoporotic VFs in good quality population studies in Europe range between 8 and 26\% for women and $7-24 \%$ for men aged 50 years and older, with lowest rates for The Netherlands and highest rates for Scandinavia [24, 25]. Of note, reported rates of VFs depend on the definition of VFs - clinical or radiographic. Moreover, radiographic deformities can be classified as fractures based on morphometric or morphologic criteria [22]. The spectrum of classifications with a focus on morphometry alone comprises at least seven methods, with more or less overlap in their definitions [15]. We chose the semi-quantitative method by Genant to classify VFs [21], because we had sufficient experience with its application on sagittal CT reformation $[18,26-30]$ and it is the most widely used tool in population studies [15, 31].

With these limitations considered, we found a considerable higher fracture prevalence for men (32\% vs. $24 \%$ ) and a rate on par for women (26\%) compared to the highest rate reported in the European population [25]. Moreover, a recent UK audit reported a fracture prevalence of $21.4 \%$ in CT imaging review of 6357 patients aged 70 years and older as seen in different radiology departments across the country [17]. A higher prevalence of osteoporotic fractures could partly be explained by a majority of $>75 \%$ being cancer patients in our study cohort, because cancer treatment 
Table 2 Counts and prevalence rates with $95 \%$ confidence intervals of patients with $\geq 1$ osteoporotic vertebral fractures (VFs) stratified by age and sex

\begin{tabular}{|c|c|c|c|c|c|c|c|c|c|c|c|c|}
\hline \multirow{3}{*}{$\begin{array}{l}\text { Age } \\
\text { Years }\end{array}$} & \multicolumn{4}{|c|}{ Women } & \multicolumn{4}{|c|}{ Men } & \multicolumn{4}{|c|}{ Total } \\
\hline & \multirow{2}{*}{$\begin{array}{l}\text { All } \\
n\end{array}$} & \multicolumn{3}{|c|}{$\begin{array}{l}\text { With } \geq 1 \text { osteoporotic } \\
\text { VF }\end{array}$} & \multirow{2}{*}{$\begin{array}{l}\text { All } \\
n\end{array}$} & \multicolumn{3}{|c|}{ With $\geq 1$ osteoporotic VF } & \multirow{2}{*}{$\begin{array}{l}\text { All } \\
n\end{array}$} & \multicolumn{3}{|c|}{ With $\geq 1$ osteoporotic VF } \\
\hline & & $n$ & $\%$ & $95 \% \mathrm{CI}$ & & $n$ & $\%$ & $95 \% \mathrm{CI}$ & & $n$ & $\%$ & $95 \% \mathrm{CI}$ \\
\hline$<50$ & 9 & 2 & 22.2 & $4.9-54.4$ & 20 & 5 & 25 & $10.2-46.4$ & 29 & 7 & 24.1 & $11.5-41.6$ \\
\hline $50-59$ & 32 & 5 & 15.6 & $6.2-30.9$ & 79 & 17 & 21.5 & $13.6-31.5$ & 111 & 22 & 19.8 & $13.2-28.0$ \\
\hline $60-69$ & 66 & 15 & 22.7 & $13.9-33.9$ & 134 & 48 & 35.8 & $28.1-44.2$ & 200 & 63 & 31.5 & $25.4-38.2$ \\
\hline 70-79 & 103 & 29 & 28.2 & $20.2-37.4$ & 185 & 63 & 34.1 & $27.5-41.1$ & 288 & 92 & 31.9 & $26.8-37.5$ \\
\hline $80+$ & 18 & 9 & 50 & $28.4-71.6$ & 72 & 26 & 36.1 & $25.7-47.6$ & 90 & 35 & 38.9 & $29.3-49.2$ \\
\hline Total & 228 & 60 & 26.3 & $20.9-32.3$ & 490 & 159 & 32.5 & $28.4-36.7$ & 718 & 219 & 30.5 & $27.2-33.9$ \\
\hline
\end{tabular}

$\mathrm{CI}=95 \%$ confidence interval can cause or worsen osteoporosis, especially when hypogonadism can occur [32]. Moreover, the high proportion of men with vascular pathology could have caused the relatively high prevalence of VFs in men, because there were numerically more patients with osteoporotic VFs who had CT angiography. This finding is supported by the notion of an osteoporosis-arterial calcification syndrome that draws a link between osteoporosis and cardiovascular disease [33, 34].

By the age of $\geq 80$ years, we found that fracture prevalence in women surpassed that of men, but the calculated rates are unreliable due to the limited number of included patients of this age. However, it is likely to assume that fracture prevalence in women aged $\geq 80$ years surpassed that of men. This dynamic in fracture prevalence between men and women seem to be reflected by a lower BMD in women beyond the age of 60 years compared to men [35].

We investigated the prevalence and reporting rate of VFs in CT in a selected clinical population of $>700$ men and women emphasizing on the lost potential for osteoporosis screening. Therefore, we juxtapose the high prevalence of VFs and the low clinical awareness of osteoporosis/low bone

Table 3 Bone-health related information in medical records

\begin{tabular}{lll}
\hline & $n$ & $\%$ \\
\hline Osteoporosis or low bone mass excluded & 4 & 0.6 \\
$\begin{array}{l}\text { Established diagnosis of osteoporosis or low } \\
\quad \text { bone mass }\end{array}$ & 38 & 5.3 \\
No information about bone health & 676 & 94.1 \\
Total & 718 & \\
\hline
\end{tabular}

mass. Despite the relatively high prevalence of osteoporotic VFs, there was no reference to bone health in clinical records of $94 \%$ of all patients. Furthermore, radiology reports of CT imaging did not mention a VF or decreased bone quality in $58 \%$ of fractured patients. While these patients pass through hospital care, a diagnosis with potentially far-reaching
Table 4 Information in CT radiology reports of fractured patients

\begin{tabular}{lll}
\hline & $n$ & $\%$ \\
\hline $\begin{array}{l}\text { No vertebral fracture (VF) or deteriorated bone qual- } \\
\text { ity* mentioned }\end{array}$ & 128 & 58.4 \\
VF mentioned & 54 & 24.7 \\
Secondary terminology** used & 21 & 9.6 \\
Secondary terminology used and deteriorated bone & 5 & 2.3 \\
$\quad$ quality mentioned & & \\
Only deteriorated bone quality mentioned & 11 & 5 \\
Total & 219 &
\end{tabular}

*Including terminology describing deteriorated bone quality, e.g. "osteopenia", "osteopenic bone structure", or "decrease bone mineral content"; **Including secondary terminology for vertebral abnormality: "deformity", "sintering", "impression", "height loss", "height reduction", or "Schmorl's node"

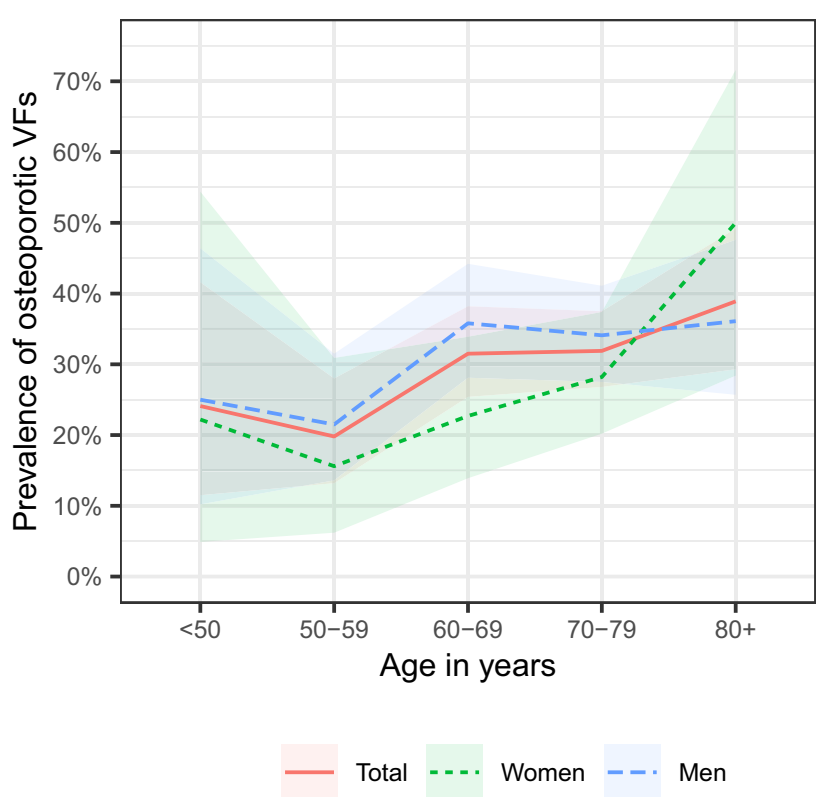

Fig. 4 Sex-specific prevalence of osteoporotic vertebral fractures (VFs) plotted by age-group and with $95 \%$ confidence intervals 
consequences on morbidity, mortality, and quality of life does not receive attention.

The diagnostic gap due to radiologic reports not mentioning prevalent vertebral fractures has been documented for the last 20 years, first in radiographs, and then in CT imaging. Concerning radiographs, there is a multinational prospective study evaluating lateral radiographs of the thoracolumbar spine [36] and a study of $>900$ hospitalized women evaluating lateral chest radiographs [37]. The latter reported that only $17 \%$ of fractured patients had fracture written in the medical record and only $50 \%$ of contemporaneous radiology reports mentioned a present fracture [36]. Concerning CT imaging, there are several studies, partly with thoracic or abdominal spine coverage only, that present reporting rates of VFs ranging from 0 to $38 \%$ [17, 37-43]. If we focus on studies including the entire thoracolumbar spine, we can find a trend towards higher reporting rates in recent years with $32.5 \%$ in 2014/2015 [43] and $45.2 \%$ in 2019 [17]. The reporting rate of $24.7 \%$ we found for CT reports written between 2008 and 2017 fits into this line. Hence, we can postulate a still large, but decreasing diagnostic gap over recent years.

We found that a little less than one-third of CT reports that mentioned vertebral anomalies in patients used secondary terminology instead of the preferred terminology "fracture". One part of the problem with underdiagnosed VFs likely stems from a lack of standard terminology in the radiologic report, while another part can be attributed to low detection rates $[17,36]$. Computer-aided diagnosis using automatic algorithms to detect VF could help improve detection rates [44, 45]. Being able to diagnose osteoporosis in patients with increased fracture risk before an initial fracture occurs should be the goal. Fracture risk assessment can be complemented by BMD assessment and can manifest the diagnosis of osteoporosis [46, 47]. Recently, a fully automatic framework for opportunistic BMD screening in any CT scans including parts of the thoracolumbar spine has been presented [29].

Bringing osteoporosis to clinical attention allows initiating physical or pharmacologic treatment to prevent future fractures $[12,48]$. However, the diagnostic gap is followed by a treatment gap. This gap stayed at a constant level of around $65 \%$ in Denmark in the years 2005 to 2014 [49]. In Catalonia and the UK, the treatment gap even increased from 2005 to 2015 [50].

This study has limitations. First, there might be a selection bias due to our inclusion criterion of CT scans covering at least vertebrae $\mathrm{T} 6$ to $\mathrm{L} 4$ and due to the exclusion of patients without a medical history of at least 5 years in this hospital. Second, we had a limited number of fractured patients in certain age groups, particularly in younger and older women, thus, limiting the statistical confidence of the reported prevalence rates. Third, data extracted from medical notes was partly sparse reducing statistical power.
In conclusion, the relatively high prevalence of osteoporotic VFs in patients with CT imaging and long-term hospital records and the still high—but seemingly decreasing — reporting gap convey a chance to significantly improve osteoporosis care. Moreover, we were able to underline the significance of clinical factors in fracture risk assessment such as prolonged prescription of pain medication. These results are in line with current approaches to osteoporosis risk assessment that can help alleviate the burden caused by osteoporosis-related fractures on individuals and healthcare systems [51].

Supplementary Information The online version contains supplementary material available at https://doi.org/10.1007/s00198-021-06169-x.

Funding Open Access funding enabled and organized by Projekt DEAL. This study has received funding from the European Research Council (ERC) und the European Union's Horizon 2020 research and innovation programme (grant agreement No 963904 - Bonescreen - ERC-2020-POC-LS) and from the German Research Foundation (Deutsche Forschungsgemeinschaft, DFG; project No 432290010).

Data availability Data availability is restricted due to ethical considerations.

Code availability Not applicable.

\section{Declarations}

Ethics approval The study was approved by the local institutional review board (ethics committee's reference number 5022/11-A2) and was conducted in accordance with the Declaration of Helsinki.

Consent to participate/for publication The requirement for informed consent was waived by the institutional review board due to the retrospective character of this study.

\section{Conflicts of interest None.}

Open Access This article is licensed under a Creative Commons Attribution-NonCommercial 4.0 International License, which permits any non-commercial use, sharing, adaptation, distribution and reproduction in any medium or format, as long as you give appropriate credit to the original author(s) and the source, provide a link to the Creative Commons licence, and indicate if changes were made. The images or other third party material in this article are included in the article's Creative Commons licence, unless indicated otherwise in a credit line to the material. If material is not included in the article's Creative Commons licence and your intended use is not permitted by statutory regulation or exceeds the permitted use, you will need to obtain permission directly from the copyright holder. To view a copy of this licence, visit http://creativecommons.org/licenses/by-nc/4.0/.

\section{References}

1. National Institutes of Health (2001) Osteoporosis prevention, diagnosis, and therapy. JAMA 285:785-795

2. Johnell O, Kanis JA (2006) An estimate of the worldwide prevalence and disability associated with osteoporotic 
fractures. Osteoporos Int 17:1726-1733. https://doi.org/10.1007/ s00198-006-0172-4

3. Cooper C, O'Neill T, Silman A (1993) The epidemiology of vertebral fractures. European Vertebral Osteoporosis Study Group. Bone 14 Suppl 1:S89-97

4. Fink HA, Milavetz DL, Palermo L et al (2005) What proportion of incident radiographic vertebral deformities is clinically diagnosed and vice versa? J Bone Miner Res 20:1216-1222. https://doi.org/ 10.1359/JBMR.050314

5. Ensrud KE (2013) Epidemiology of fracture risk with advancing age. J Gerontol A Biol Sci Med Sci 68:1236-1242. https://doi.org/ 10.1093/gerona/glt092

6. Klotzbuecher CM, Ross PD, Landsman PB et al (2000) Patients with prior fractures have an increased risk of future fractures: a summary of the literature and statistical synthesis. J Bone Miner Res 15:721-739. https://doi.org/10.1359/jbmr.2000.15.4.721

7. Bliuc D, Nguyen ND, Milch VE et al (2009) Mortality risk associated with low-trauma osteoporotic fracture and subsequent fracture in men and women. JAMA 301:513-521. https://doi.org/10. 1001/jama.2009.50

8. Center JR, Nguyen TV, Schneider D et al (1999) Mortality after all major types of osteoporotic fracture in men and women: an observational study. Lancet 353:878-882. https://doi.org/10.1016/ S0140-6736(98)09075-8

9. Center JR (2017) Fracture burden: what two and a half decades of Dubbo Osteoporosis Epidemiology Study data reveal about clinical outcomes of osteoporosis. Curr Osteoporos Rep 15:88-95. https://doi.org/10.1007/s11914-017-0352-5

10. Adachi JD, Lyles KW, Colón-Emeric CS et al (2011) Zoledronic acid results in better health-related quality of life following hip fracture: the HORIZON-Recurrent Fracture Trial. Osteoporos Int 22:2539-2549. https://doi.org/10.1007/s00198-010-1514-9

11. Lyles KW, Colón-Emeric CS, Magaziner JS et al (2007) Zoledronic acid and clinical fractures and mortality after hip fracture. N Engl J Med 357:1799-1809. https://doi.org/10.1056/NEJMo a074941

12. Compston JE, McClung MR, Leslie WD (2019) Osteoporosis. Lancet 393:364-376. https://doi.org/10.1016/S0140-6736(18) 32112-3

13. van der Klift M, de Laet CEDH, McCloskey EV et al (2004) Risk factors for incident vertebral fractures in men and women: the Rotterdam Study. J Bone Miner Res 19:1172-1180. https://doi. org/10.1359/JBMR.040215

14. Melton LJ, Atkinson EJ, Cooper C et al (1999) Vertebral fractures predict subsequent fractures. Osteoporos Int 10:214-221

15. Ballane G, Cauley JA, Luckey MM, El-Hajj Fuleihan G (2017) Worldwide prevalence and incidence of osteoporotic vertebral fractures. Osteoporos Int 28:1531-1542. https://doi.org/10.1007/ s00198-017-3909-3

16. Löffler MT, Sollmann N, Mei K et al (2020) X-ray-based quantitative osteoporosis imaging at the spine. Osteoporos Int 31:233250. https://doi.org/10.1007/s00198-019-05212-2

17. Howlett DC, Drinkwater KJ, Mahmood N et al (2020) Radiology reporting of osteoporotic vertebral fragility fractures on computed tomography studies: results of a UK national audit. Eur Radiol:111.https://doi.org/10.1007/s00330-020-06845-2

18. Bauer JS, Müller D, Ambekar A et al (2006) Detection of osteoporotic vertebral fractures using multidetector CT. Osteoporos Int 17:608-615. https://doi.org/10.1007/s00198-005-0023-8

19. Oei L, Koromani F, Breda SJ et al (2018) Osteoporotic vertebral fracture prevalence varies widely between qualitative and quantitative radiological assessment methods: The Rotterdam Study. J Bone Miner Res 33:560-568. https://doi.org/10.1002/jbmr.3220

20. Panaroni C, Yee AJ, Raje NS (2017) Myeloma and bone disease. Curr Osteoporos Rep 15:483-498. https://doi.org/10.1007/ s11914-017-0397-5
21. Genant HK, Wu CY, van Kuijk C, Nevitt MC (1993) Vertebral fracture assessment using a semiquantitative technique. J Bone Miner Res 8:1137-1148. https://doi.org/10.1002/jbmr.5650080915

22. Lentle B, Koromani F, Brown JP et al (2019) The radiology of osteoporotic vertebral fractures revisited. J Bone Miner Res 34:409-418. https://doi.org/10.1002/jbmr.3669

23. Link TM, Guglielmi G, van Kuijk C, Adams JE (2005) Radiologic assessment of osteoporotic vertebral fractures: diagnostic and prognostic implications. Eur Radiol 15:1521-1532. https:// doi.org/10.1007/s00330-005-2773-2

24. Van der Klift M, De Laet CEDH, McCloskey EV et al (2002) The incidence of vertebral fractures in men and women: the Rotterdam Study. J Bone Miner Res 17:1051-1056. https://doi.org/10.1359/ jbmr.2002.17.6.1051

25. O'Neill TW, Felsenberg D, Varlow J et al (1996) The prevalence of vertebral deformity in European men and women: the European Vertebral Osteoporosis Study. J Bone Miner Res 11:1010-1018. https://doi.org/10.1002/jbmr.5650110719

26. Baum T, Bauer JS, Klinder T et al (2014) Automatic detection of osteoporotic vertebral fractures in routine thoracic and abdominal MDCT. Eur Radiol 24:872-880. https://doi.org/10.1007/ s00330-013-3089-2

27. Schwaiger BJ, Gersing AS, Baum T et al (2014) Bone mineral density values derived from routine lumbar spine multidetector row CT predict osteoporotic vertebral fractures and screw loosening. AJNR Am J Neuroradiol 35:1628-1633. https://doi.org/10. 3174/ajnr.A3893

28. Löffler MT, Jacob A, Valentinitsch A et al (2019) Improved prediction of incident vertebral fractures using opportunistic QCT compared to DXA. Eur Radiol. https://doi.org/10.1007/ s00330-019-06018-w

29. Löffler MT, Jacob A, Scharr A et al (2021) Automatic opportunistic osteoporosis screening in routine CT: improved prediction of patients with prevalent vertebral fractures compared to DXA. Eur Radiol. https://doi.org/10.1007/s00330-020-07655-2

30. Löffler MT, Sekuboyina A, Jacob A et al (2020) A vertebral segmentation dataset with fracture grading. Radiol Artif Intell 2:e190138. https://doi.org/10.1148/ryai.2020190138

31 Lentle BC (2020) Gender and the recognition of vertebral fractures. Quant Imaging Med Surg 10:1401-1407. https://doi.org/10. 21037/qims.2020.04.12

32. Pfeilschifter J, Diel IJ (2000) Osteoporosis due to cancer treatment: pathogenesis and management. J Clin Oncol 18:1570-1593. https://doi.org/10.1200/JCO.2000.18.7.1570

33. Hofbauer LC, Brueck CC, Shanahan CM et al (2007) Vascular calcification and osteoporosis-from clinical observation towards molecular understanding. Osteoporos Int 18:251-259. https://doi. org/10.1007/s00198-006-0282-z

34. Farhat GN, Cauley JA (2008) The link between osteoporosis and cardiovascular disease. Clin Cases Miner Bone Metab 5:19-34

35. Pickhardt PJ, Lee SJ, Liu J et al (2019) Population-based opportunistic osteoporosis screening: validation of a fully automated CT tool for assessing longitudinal BMD changes. Br J Radiol 92:20180726. https://doi.org/10.1259/bjr.20180726

36. Delmas PD, van de Langerijt L, Watts NB et al (2005) Underdiagnosis of vertebral fractures is a worldwide problem: the IMPACT study. J Bone Miner Res 20:557-563. https://doi.org/10.1359/ JBMR.041214

37. Williams AL, Al-Busaidi A, Sparrow PJ et al (2009) Under-reporting of osteoporotic vertebral fractures on computed tomography. Eur J Radiol 69:179-183. https://doi.org/10.1016/j.ejrad.2007.08. 028

38. Woo EK, Mansoubi H, Alyas F (2008) Incidental vertebral fractures on multidetector CT images of the chest: prevalence and recognition. Clin Radiol 63:160-164. https://doi.org/10.1016/j. crad.2007.01.031 
39. Bartalena T, Giannelli G, Rinaldi MF et al (2009) Prevalence of thoracolumbar vertebral fractures on multidetector CT: underreporting by radiologists. Eur J Radiol 69:555-559. https://doi. org/10.1016/j.ejrad.2007.11.036

40. Müller D, Bauer JS, Zeile M et al (2008) Significance of sagittal reformations in routine thoracic and abdominal multislice $\mathrm{CT}$ studies for detecting osteoporotic fractures and other spine abnormalities. Eur Radiol 18:1696-1702. https://doi.org/10.1007/ s00330-008-0920-2

41. Obaid H, Husamaldin Z, Bhatt R (2008) Underdiagnosis of vertebral collapse on routine multidetector computed tomography scan of the abdomen. Acta Radiol 49:795-800. https://doi.org/10.1080/ 02841850802165776

42. Carberry GA, Pooler BD, Binkley N et al (2013) Unreported vertebral body compression fractures at abdominal multidetector CT. Radiology 268:120-126. https://doi.org/10.1148/radiol.13121632

43. Urrutia J, Besa P, Piza C (2019) Incidental identification of vertebral compression fractures in patients over 60 years old using computed tomography scans showing the entire thoraco-lumbar spine. Arch Orthop Trauma Surg 139:1497-1503. https://doi.org/ 10.1007/s00402-019-03177-9

44. Burns JE, Yao J, Summers RM (2017) Vertebral body compression fractures and bone density: automated detection and classification on CT images. Radiology 284:788-797. https://doi.org/ 10.1148/radiol.2017162100

45. Dagan N, Elnekave E, Barda N et al (2020) Automated opportunistic osteoporotic fracture risk assessment using computed tomography scans to aid in FRAX underutilization. Nat Med 26:77-82. https://doi.org/10.1038/s41591-019-0720-Z
46. Engelke K, Adams JE, Armbrecht G et al (2008) Clinical use of quantitative computed tomography and peripheral quantitative computed tomography in the management of osteoporosis in adults: the 2007 ISCD Official Positions. J Clin Densitom 11:123-162. https://doi.org/10.1016/j.jocd.2007.12.010

47. Kanis JA, Harvey NC, McCloskey E et al (2020) Algorithm for the management of patients at low, high and very high risk of osteoporotic fractures. Osteoporos Int 31:1-12. https://doi.org/ 10.1007/s00198-019-05176-3

48. Kendler DL, Bauer DC, Davison KS et al (2016) Vertebral fractures: clinical importance and management. Am J Med 129:221. e1-10. https://doi.org/10.1016/j.amjmed.2015.09.020

49. Skjødt MK, Ernst MT, Khalid S et al (2021) The treatment gap after major osteoporotic fractures in Denmark 2005-2014: a combined analysis including both prescription-based and hospital-administered anti-osteoporosis medications. Osteoporos Int. https://doi.org/10.1007/s00198-021-05890-x

50. Skjødt MK, Khalid S, Ernst M et al (2020) Secular trends in the initiation of therapy in secondary fracture prevention in Europe: a multi-national cohort study including data from Denmark, Catalonia, and the United Kingdom. Osteoporos Int 31:1535-1544. https://doi.org/10.1007/s00198-020-05358-4

51. Curtis EM, Moon RJ, Harvey NC, Cooper C (2017) The impact of fragility fracture and approaches to osteoporosis risk assessment worldwide. Bone 104:29-38. https://doi.org/10.1016/j.bone.2017. 01.024

Publisher's note Springer Nature remains neutral with regard to jurisdictional claims in published maps and institutional affiliations. 